\title{
FAKTOR YANG BERHUBUNGAN TENTANG P4K DENGAN KESIAPAN PERSALINAN DI KELURAHAN PARUPUK TABING
}

\author{
Abdi Iswahyudi Yasril ${ }^{1}$, Widya Rahmadani ${ }^{2}$ \\ Program Studi Ilmu Kesehatan Masyarakat, Sekolah Tinggi Ilmu Kesehatan Fort De \\ Kock Bukittinggi \\ iswahyudiabdi2893@gmail.com
}

Submitted: 02-04-2019, Reviewer: 05-05-2019, Accepted: 17-07-2019

\begin{abstract}
The Birth Prevention and Complication Prevention (P4K) Program is performed because of the complication and AKI tillage. Based on the Health Profile of West Sumatra, the 2015 complication is 58.0\%. Padang City is one of West Sumatera Province which has 33,10\% complication from 22 healtcare. The purpose of this research is to know the relation of knowledge, attitude of pregnant mother and husband support about P4K with the readiness of delivery in Parupuk Tabing Urban Village in 2017. This research use crossectional design with proportional sampling technique. The object in this research is pregnant women in Parupuk Tabing urban district. To know the relationship of knowledge, attitude and support of husband about P4K with the laborreadiness is tested by Chi-Square test with degree of trust $95 \%$. The statistical test showed that there is a correlation between mother's knowledge level $(p=0,046)$, attitude $(p=0,048)$ and husband support $(p=0,001)$ to P4K with the readiness of labor. It was concluded that there was a relationship of knowledge, attitude of pregnant mother about $P 4 K$ with the readiness of persalian. To the husband is expected to take the time to accompany the mother to examine her pregnancy, and provide support to prepare for delivery according to P4K Program.
\end{abstract}

Keywords: Knowledge, Attitude, Husband Support, P4K, Readiness Birth

\begin{abstract}
ABSTRAK
Program Perencanaan Persalinan dan Pencegahan Komplikasi (P4K) dilakukan karena tinginya komplikasi dan AKI. Berdasarkan Profil Kesehatan Sumatera Barat, komplikasi tahun 2015 adalah 58,0\%. Kota Padang merupakan salah satu Provinsi di Sumatera Barat yang mempunyai komplikasi sebesar 33,10\% dari 22 Puskesmas yang ada, Tujuan penelitian ini untuk mengetahui hubungan pengetahuan, sikap ibu hamil dan dukungan suami tentang P4K dengan kesiapan persalinan di Kelurahan Parupuk Tabing tahun 2017. Penelitian ini menggunakan desain Crossectional dengan teknik sampel Proportional sampling. Objek penelitian adalah ibu hamil yang ada di Kelurahan Parupuk Tabing. Untuk mengetahui hubungan pengetahuan, sikap dan dukungan suami tentang $\mathrm{P} 4 \mathrm{~K}$ dengan kesiapan persalinan diuji dengan uji Chi-Square dengan derajat kepercayaan $95 \%$. Hasil penelitian menunjukkan tingkat. Uji statistik menunjukkan bahwa ada hubungan antara tingkat pengetahuan ibu ( $\mathrm{p}=$ $0,046)$, sikap $(\mathrm{p}=0,048)$ dan dukungan suami $(\mathrm{p}=0,001)$ tentang $\mathrm{P} 4 \mathrm{~K}$ dengan kesiapan persalinan. Disimpulkan ada hubungan pengetahuan, sikap ibu hamil tentang P4K dengan kesiapan persalianan. Kepada suami diharapkan untuk dapat meluangkan waktu untuk menemani ibu memeriksaan kehamilannya, dan memberikan dukungan untuk mempersiapkan persalinan sesuai Program P4K.
\end{abstract}

Kata kunci: Pengetahuan, Sikap, Dukungan Suami, P4K, Kesiapan Persalinan 


\section{PENDAHULUAN}

Pelaksanaan program P4K dilakukan karena melihat tingginya AKI, maka diperlukan strategi untuk mencegah kematian tersebut dengan cara pemberdayaan perempuan, keluarga dan masyarakat serta kerja sama lintas sektor, termasuk pemerintah daerah. Salah satu cara untuk melaksanakan strategi tersebut adalah Program Perencanaan Persalinan dan Pencegahan Komplikasi (P4K) yang menitik beratkan fokus totalitas pemantauan yang menjadi salah satu upaya deteksi dini, menghindari risiko kesehatan pada ibu hamil serta menyediakan akses dan pelayanan kegawat daruratan kebidanan dan bayi baru lahir dasar di tingkat Puskesmas (PONED) dan pelayanan kegawat daruratan obstetric dan neonatal komprehensif di Rumah Sakit (PONEK). Stiker P4K memuat data tentang nama ibuhamil, perkiraan tanggal persalinan, penolong persalinan,tempat persalinan, pendamping persalinan, transportasiyang akan digunakan, sampai calon donor darah (Depkes RI, 2014).

Meningkatkan kesehatan ibu adalah salah satu tujuan Sustainable Development Goals Summit (SDGs) yang merupakan lanjutan dari MDGs. Jika ingin memperoleh hasil yang baik dalam SDGs untuk 1,5 dkd kedepan maka target yang telah ditentukan SDGs adalah penurunan AKI adalah 70 /100.000 kelahiran hidup (WHO, 2016)

Menurut penelitian Erni, dkk (2015) sikap ibu hamil terhadap perencanaan pertolongan persalinan dan pencegahan komplikasi mempunyai hubungan yang signifikan $(p=0,0005)$. Hal ini sesuai dengan penelitian Riani (2016) juga menyatakan bahwa dukungan suami ibu hamil trimester III terhadap P4K dengan kepatuhan dalam melaksanakan P4K mempunyai hubungan yang signifikan $(\mathrm{OR}=18,960 ; 95 \% \mathrm{CI}$ $: 2,1-6,6 ; p=0,01)$.

Penelitian lain juga menyebutkan tentang hubungan tingkat pengetahuan ibu hamil tentang $\mathrm{P} 4 \mathrm{~K}$ dengan penggunaan stiker P4K di Desa Mijen Kecamatan Kaliwungu Kabupaten Kudus. Menyebutkan bahwa ada hubungan yang bermakna antara tingkat pengetahuan dengan penggunaan stiker P4K.

Komplikasi maternal tahun 2015 di Provinsi Sumatera Barat adalah sebesar 22.369 orang. Pencapaian Penanganan Komplikasi ibu hamil, bersalin dan nifas di Provinsi Sumatera Barat tahun 2015 sebesar 58,0 \%, angka ini belum mencapai target yang ditetapkan sebesar 75\% (Dinas Kesehatan Provinsi Sumatera Barat, 2015).

Pada tahun 2016, penanganan komplikasi kebidanan di Kota Padang sebanyak $1.222 \quad(33,10 \%)$ dari 3.688 perkiraan ibu hamil dengan komplikasi. Cakupan ini turun dari tahun sebelumnya yaitu sebesar 34,76\%. komplikasi tertinggi untuk kota Padang terdapat di Kelurahan Parupuk Tabing yaitu berjumlah 428 orang dengan AKI sebanyak 3 orang (DKK, 2016).

Berdasarkan hasil dari survei pendahuluan yang peneliti lakukan pada di Kelurahan Parupuk Tabing, dari 5 orang ibu hamil, 2 orang mengalami komplikasi yaitu Anemia dan hipertensi, 3orang tidak lengkap dalam mempersiapkan persalinannya yaitu belum menentukan tempat melahirkan,belum memilih tenaga kesehatan dan belum menyiapkan donor darah, 4 orang memiliki pengetahuan yang rendah tentang $\mathrm{P} 4 \mathrm{~K}, 3$ orang memiliki sikap yang kurang tentang $\mathrm{P} 4 \mathrm{~K}$ yaitu tidak peduli dengan stiker yang tertempel didepan rumah, serta 2 orang tidak mendapatkan dukungan yang positif dari suaminya terhadap persiapan persalinan yaitu suami belum mendiskusikan dimana tempat melahirkan dan siapa penolong persalinan.

Berdasarkan data yang ditemukan pada salah satu puskesmas yang ada di Kota Padang dimana jumlah komplikasi psca salin paling banyak dan dari hasil survei pendahuluan yang dilakukan 
peneliti, maka peneliti merasa tertarik untuk melakukan penelitian tentang "Faktor yang berhubungan tentang P4K dengan kesiapan persalinan di Kelurahan Parupuk Tabing".

\section{METODE PENELITIAN}

Penelitian ini merupakan jenis penelitian survey analitik dengan menggunakan desain crossectional study. Penelitian ini dilaksanakan pada bulan Agustus di Kelurahan Parupuk Tabing tahun 2017. Populasi dalam penelitian ini adalah 509 responden dengan sampel 41 responden. Teknik pengambilan sampel dengan menggunakan Proportional sampling. Analisa data menggunakan Univariat dan Bivariat yaitu dengna Uji Chis- Square. Alat ukur menggunakan kuesioner.

\section{HASIL DAN PEMBAHASAN Analisis Univariat}

Pada penelitian ini akan membahas tentang hasil univariat dan hasil bivariat. Sesuai dengan hasil penelitian bahwa disteribusi frekuensi dapat dilihat pada tabel 1. Pada tabel 1 didapatkan bahwa sebagian besar distribusi frekuensi pengetahuan ibu tentang P4K di Kelurahan Parupuk Tabing tahun 2017 yaitu sebanyak 23 ibu $(56,1 \%)$ berpengetahuan rendah.
Rendahnya

pengetahuan dikelurahan parupuk tabing terlihat dari bahwa responden tidak mengetahui tujuan dari P4K. Karena tujuan dari P4K adalah agar sasaran bisa terdata dan dapat meningkatkan cakupan serta mutu pelayanan kesehatan bagi ibu hamil dan bayi baru lahir melalui peningkatan peran aktif keluarga, masyarakat sehingga ibu melahirkan dengan aman.

Pada variabel sikap sesuai dengan tabel 1, lebih dari separuh distribusi frekuensi sikap ibu tentang P4K di Kelurahan Parupuk Tabing tahun 2017 yaitu sebanyak $25 \mathrm{ibu}(61 \%)$ mempunyai sikap negatif tentang P4K. Hal ini disebabkan karena kurang memahami tentang program ini. Dari sikap ibu terlihat bahwa ibu tidak memahami bahwasanya persiapan persalinan itu penting dan menganggap kehamilan mereka sehat - sehat saja dan baru menentukan penolong serta tempat bersalin ketika usia kehamilan hampir atau sudah 9 bulan sehingga program P4K tidak diikuti. Maka dari itu ibu seharusnya merubah kebiasaan buruk yang sudah menjadi budaya tersebut dan bidan perlu meningkatkan kualitas pemberian informasi pada ibu hamil tentang persiapan persalinan, keuntungan dari persiapan persalinan yang lengkap sesuai dengan stiker $\mathrm{P} 4 \mathrm{~K}$ agar pelaksanaan $\mathrm{P} 4 \mathrm{~K}$ sesuai yang diharapkan.

Tabel 1. Distribusi Frekuensi Pengetahuan, Sikap, Dukungan Suami dan Kesiapan Persalinan

\begin{tabular}{ccc}
\hline Pengetahuan Ibu & Frekuensi & Persentase (\%) \\
\hline Rendah & 23 & 56,1 \\
Tinggi & 18 & 43,9 \\
\hline Total & $\mathbf{4 1}$ & $\mathbf{1 0 0 , 0 0}$ \\
\hline Sikap & Frekuensi & Persentase (\%) \\
\hline Negatif & 25 & 61 \\
Positif & 16 & 39 \\
\hline Total & $\mathbf{4 1}$ & $\mathbf{1 0 0 , 0 0}$ \\
\hline Dukungan suami & Frekuensi & Persentase (\%) \\
\hline Negatif & 21 & 51,2 \\
Positif & 20 & $\mathbf{1 0 0 , 0 0}$ \\
\hline Total & $\mathbf{4 1}$ & Persentase (\%) \\
\hline Kesiapan Persalinan & Frekuensi & 53,7 \\
\hline Kurang Baik & 22 & 46,3 \\
\hline Baik & 19 & $\mathbf{1 0 0 , 0 0}$
\end{tabular}


Pada variabel dukungan suami terlihat bahwa sebagian besar distribusi frekuensi dukungan suami tentang $\mathrm{P} 4 \mathrm{~K}$ di Kelurahan Parupuk Tabing tahun 2017 yaitu sebanyak 21 orang $(51,2 \%)$ mempunyai dukungan suami negatif tentang P4K. Banyaknya ibu hamil yang tidak mendapatkan dukungan suami disebabkan oleh kurangya pemahaman suami tentang manfaat $\mathrm{P} 4 \mathrm{~K}$, selain itu juga karena kesibukan suami dengan pekerjaannya sehingga menyebabkan kurangnya waktu untuk memberikan dorongan pada ibu hamil serta menemani ibu hamil ke tempat pelayanan kesehatan.

Kemudian pada kesiapan persalinan sesuai dengan tabel 1 bahwa hampir sebagian besar distribusi frekuensi kesiapan persalinan di Kelurahan Parupuk Tabing tahun 2017 yaitu sebanyak 22 orang $(46,3 \%)$ mempunyai kesiapan persalinan yang kurang baik. Peneliti berpendapat bahwa masih ada ibu hamil yang tidak siap terhadap persalinannya itu dipengaruhi oleh kondisi fisik, mental, pengetahuan. Dan juga ibu hamil yang mempunyai kesiapan persalinan yang kurang baik disebabkan karena kurangya pemahaman ibu dalam menghadapi persalinan, selain itu juga karena kurangnya dukungan kerabat terutama suami dalam mempersiapkan persalinan istri sehingga berisiko terlambat dalam menentukan / mengambil keputusan kepada siapa ia akan melakukan persalinan. Maka dari itu perlu dilakukan penyuluhan tentang pentingnya kesiapan persalinan kepada ibu dan kerabat dekat terutama suami sebagai kepala keluarga agar mendukung ibu dalam kesiapan persalinan sehingga ibu dapat mempersiapkan persalinannya dengan aman dan lancar.

\section{Analisa Bivariat}

Pada analisa bivariat bertujuan untuk melihat hubungan antara variabel independen dan dependen. Dalam penelitian ini peneliti ingin melihat hubungan pengetahuan, sikap dan dukungan suami tentang $\mathrm{P} 4 \mathrm{~K}$ terhadap
Kesiapan Persalinan. Hal ini dapat dilihat pada tabel 2.

\section{Hubungan Pengetahuan tentang P4K terhadap Kesiapan Persalinan}

Berdasarkan tabel 2, diperoleh nilai secara statistik dengan uji ChiSquare yaitu p-value $=0,046$. Ini menunjukkan bahwa ada hubungan antara tingkat pengetahuan ibu tentang P4K dengan kesiapan persalinan.

Hal ini didapatkan karena pengetahuan erat kaitannya dengan pengalaman seseorang untuk memperoleh pengetahuan tersebut. Menurut Notoatmodjo, (2010) pengetahuan adalah hasil dari tahu dan ini terjadi setelah orang melakukan penginderaan terhadap suatu objek tertentu. Sebagian besar pengetahuan manusia diperoleh melalui mata dan telinga. Seseorang yang berpengetahuan tinggi cendrung untuk bertindak baik dalam pemeliharaan kesehatanya begitu juga sebaliknya. Pengetahuan dapat juga diartikan sebagai informasi atau maklumat yang diketahui atau disadari oleh seseorang. Notoatmodjo, (2010) mengatakan bahwa adanya pengalaman yang seseorang dapatkan baik pengalaman pribadi maupun dari orang lain maka itu dapat menentukan status kesehatan seseorang tersebut.

Hasil penelitian ini sesuai dengan penelitian Visi Prima (2014) yang menyatakan bahwa antara pengetahuan ibu dengan kesiapan persalinan saling berhubungan ( $\mathrm{p}$ value $=0,002$ ). Sejalan dengan penelitian Hidayatun dkk (2016) yang menyatakan bahwa pengetahuan ibu berhubungan dengan kesiapan persalinan (pvalue $=0,03$ ).

Pengetahuan ibu tentang $\mathrm{P} 4 \mathrm{~K}$ dengan kesiapan persalinan masih ada yang rendah. Hal ini disebabkan masih belum jelasnya informasi yang mereka terima tentang P4K. Sehingga ibu beresiko kurang siap dalam menghadapi persalinannya. Namun masih ada ibu yang berpengetahuan rendah yang baik kesiapan persalinannya, hal ini 
disebabkan karena ibu sudah pernah menghadapi persalinan

Maka untuk menambah pengetahuan ibu dapat dilakukan dengan memberikan penyuluhan kepada ibu dan keluarga tentang pentingnya $\mathrm{P} 4 \mathrm{~K}$ sehingga ibu dapat mempersiapkan persalinannya lebih baik dan menjaga kesehatannya secara mandiri serta terhindar dari komplikasi

\section{Hubungan Sikap tentang P4K terhadap Kesiapan Persalinan}

Pada tabel 2, secara statistik diperoleh $\mathrm{p}=0,048$. Hal ini menunjukkan bahwa ada hubungan antara sikap ibu tentang P4K dengan kesiapan persalinan.

Menurut Notoadmodjo (2010) faktor yang mempengaruhi sikap seseorang adalah pengalaman pribadi, pengaruh orang lain, pengaruh kebudayaan, media masa, lembaga pendidikan, dan lembaga agama, serta faktor emosional. Sikap dalam penelitian ini adalah tanggapan dan penerimaan ibu terhadap persiapan persalinan yang terdapat pada stiker P4K.

Penelitian ini sejalan dengan penelitian yang dilakukan oleh Fitria Martanti di Banjarsari Surakarta yang menyatakan bahwa ada hubungan antara sikap dengan persiapan persalinan ( $\rho$ value $=0,02)$. Penelitian Visi Prima (2014) juga menjelaskan bahwa sikap dengan kesiapan persalinan saling berhubungan (pvalue $=0,0005<0,05$ ).

Sikap ibu tentang $\mathrm{P} 4 \mathrm{~K}$ dengan kesiapan persalinan masih banyak yang negatif. Hal itu dikarenakan ibu belum memiliki persiapan yang matang untuk persalinannya, padahal usia kehamilan ada yang sudah memasuki taksiran persalinan, ketika terjadi kegawatdaruratan maka akan berisiko terhadap kondisi ibu dan bayinya nanti. Namun masih ada 8 ibu yang

Tabel 2. Faktor Yang Berhubungan Tentang P4k Dengan Kesiapan Persalinan Di Kelurahan Parupuk Tabing

\begin{tabular}{|c|c|c|c|c|c|c|c|c|}
\hline \multirow{3}{*}{$\begin{array}{c}\text { Tingkat } \\
\text { Pengetahuan }\end{array}$} & \multicolumn{4}{|c|}{ Kesiapan Persalinan } & & & \multirow{3}{*}{ p Value } & \multirow{3}{*}{ OR $(95 \% \mathrm{CI})$} \\
\hline & \multicolumn{2}{|c|}{$\begin{array}{l}\text { Kurang } \\
\text { Baik }\end{array}$} & \multicolumn{2}{|c|}{ Baik } & \multicolumn{2}{|c|}{ Total } & & \\
\hline & $\mathrm{n}$ & $\%$ & $\mathrm{~N}$ & $\%$ & $\mathrm{~N}$ & $\%$ & & \\
\hline Rendah & 16 & 69,6 & 7 & 30,4 & 23 & 100 & \multirow{3}{*}{0,046} & \multirow{3}{*}{$\begin{array}{c}4,571 \\
(1,218-17,157)\end{array}$} \\
\hline Tinggi & 6 & 9,7 & 12 & 66,7 & 18 & 100 & & \\
\hline Total & 22 & 53,7 & 19 & 46,3 & 41 & 100 & & \\
\hline \multirow{3}{*}{ Sikap } & \multicolumn{4}{|c|}{ Kesiapan Persalinan } & \multirow{2}{*}{\multicolumn{2}{|c|}{ Total }} & \multirow{3}{*}{$\underset{\text { Value }}{\mathbf{p}}$} & \multirow{3}{*}{ OR $(95 \% \mathrm{CI})$} \\
\hline & \multicolumn{2}{|c|}{$\begin{array}{c}\text { Kurang } \\
\text { Baik }\end{array}$} & \multicolumn{2}{|c|}{ Baik } & & & & \\
\hline & $\mathrm{n}$ & $\%$ & $\mathrm{~N}$ & $\%$ & $\mathrm{n}$ & $\%$ & & \\
\hline Negatif & 17 & 68,0 & 8 & 30,4 & 25 & 100 & \multirow{3}{*}{0,048} & \multirow{3}{*}{$\begin{array}{l}4,675(1,211 \\
-18,041)\end{array}$} \\
\hline Positif & 5 & 31,2 & 11 & 66,7 & 16 & 100 & & \\
\hline Total & 22 & 53,7 & 19 & 46,3 & 58 & 100 & & \\
\hline \multirow{3}{*}{$\begin{array}{c}\text { Dukungan } \\
\text { Suami }\end{array}$} & \multicolumn{4}{|c|}{ Kesiapan Persalinan } & \multirow{2}{*}{\multicolumn{2}{|c|}{ Total }} & \multirow{3}{*}{ p Value } & \multirow{3}{*}{ OR $(95 \% \mathrm{CI})$} \\
\hline & \multicolumn{2}{|c|}{$\begin{array}{c}\text { Kurang } \\
\text { Baik }\end{array}$} & \multicolumn{2}{|c|}{ Baik } & & & & \\
\hline & $\mathrm{n}$ & $\%$ & $\mathrm{~N}$ & $\%$ & $\mathrm{n}$ & $\%$ & & \\
\hline Negatif & 17 & 81,0 & 4 & 19,0 & 21 & 100 & \multirow{3}{*}{0,001} & \multirow{3}{*}{$\begin{array}{c}12,750 \\
(2,883-56,39)\end{array}$} \\
\hline Positif & 5 & 25,0 & 15 & 75,0 & 20 & 100 & & \\
\hline Total & 22 & 53,7 & 19 & 46,3 & 41 & 100 & & \\
\hline
\end{tabular}


bersikap negatif yang baik kesiapan persalinannya, hal ini disebabkan karena ibu sudah pernah menghadapi persalinan sebelumnya.

Maka dari itu sikap ibu yang negatif harus diubah agar persiapan persalinan bisa terlaksana dengan baik sebagaimana mestinya. Peran petugas kesehatan terutama bidan diminta untuk melakukan KIE sehubungan dengan pelaksanaan $\mathrm{P} 4 \mathrm{~K}$.

\section{Hubungan Dukungan Suami tentang P4K terhadap Kesiapan Persalinan}

Sesuai dengan tabel 2 diperoleh $\mathrm{p}$ $=0,001$. Hal ini menunjukkan bahwa ada hubungan antara dukungan suami tentang $\mathrm{P} 4 \mathrm{~K}$ dengan kesiapan persalinan.

Dukungan suami menunjukan keterlibatan suami dalam kehamilan pasangannya dan persiapan yang terkait dengan anaknya (Bobak, 2013). Suami adalah orang pertama dan utama dalam memberi dorongan kepada istri sebelum pihak lain turut memberi dorongan, dukungan dan perhatian seorang suami terhadap istri yang sedang hamil yang akan membawa dampak bagi sikap bayi. Dukungan suami disini berbetuk dukungan emosional, psikologis, dukungan informasi, dan dukungan penilaian dan dukungan instrumental (Lee, 2015).

Hasil penelitian ini sesuai dengan Steppi dkk (2016) yang menyatakan bahwa ada hubungan dukungan suami dengan kesiapan persalinan $(\mathrm{p} v a l u e=$ 0,0005). Sejalan dengan Mardiyaningsih (2012) yang menyatakan bahwa dukungan suami berhubungan dengan kesiapan persalinan ( $\mathrm{p}$ value $=0,011<0,05)$.

Menurut asumsi peneliti, kurangnya dukungan suami disebabkan karena kesibukan dimana suami berada diluar rumah lebih dari 24 jam Karena banyak yang berprofesi sebagai nelayan. Sehingga waktu bersama istri kurang. Suami juga mengeluhkan lelah setiap sampai dirumah. Sikap seperti ini membuat istri tidak termotivasi untuk melakuakan pemeriksaan kehamilan tanpa didamping suami. Oleh karena itu diharapkan pada suami agar dapat meluangkan waktu menemani istri dan memberi motivasi untuk memeriksaan kehamilan sehingga dapat mempersiapkan persalinan yang aman

\section{SIMPULAN}

Sesuai dengan hasil penelitian didapatkan dari 3 variabel, semuanya mempunyai hubungan signifikan terhadap kesiapan persalinan, namun yang paling signifikan adalah dukungan suami dengan $\mathrm{P}$-value $=0,001$. Maka dari itu sesuai dengan hasil penelitian diharapkan kepada suami agar dapat meluangkan waktu untuk menemani ibu ke tempat pelayanan kesehatan memeriksaan kehamilannya, dan memberikan dukungan untuk mempersiapkan persalinan.

Bagi para petugas terutama bidan untuk meningkatkan penyuluhan tentang pentingnya kesiapan persalinan sesuai dengan stiker P4K pada ibu hamil melalui posyandu, K1, K4, kunjungan kerumah, pemasangan pamlet - pamflet dan penyebaraan brosur - brosur sehingga ibu memahami dan dapat mengaplikasikan betapa pentingnya kesiapan persalinan sesuai stiker P4K.

\section{UCAPAN TERIMA KASIH}

Terima kasih diucapkan kepada LPPM STIKes Fort De Kock yang telah memfasilitasi penelitian ini. Selanjutnya, terima kasih juga dihaturkan kepada seluruh responden atas partisipasinya dalam terlaksananya penelitian ini.

\section{DAFTAR PUSTAKA}

Bobak, 2013. Buku Ajar Keperawatan Maternitas. Medical Book.

Depkes RI. 2015.Pedoman program perencanaan persalinan dan pencegahan kompikasi (P4K) dengan stiker: dalam rangka mempercepat penurunan AKI Jakarta: Depkes RI

Depkes RI, 2014. Profil kesehatan 
Indonesia tahun 2013. Jakarta: Depkes RI.

Dinas Kesehatan Kota Padang. 2017.Laporan tahunan bulanan 2017. Edisi Terbit tahun2017. Padang : Dinas Kesehatan Kota Padang.

Dinas Kesehatan Provinsi Sumatera Barat, 2015. Profil kesehatan Sumatera Barat tahun 2014. Padang: Dinas Kesehatan Provinsi Sumbar.

Erni, Rafidah, and Hapisah. 2015.Pengetahuan dan Sikap Ibu Hamil Terhadap Perencanaan Pertolongan Persalinan dan Pencegahan Komplikasi (P4K).Jurnal Vokasi Kesehatan. 1 (5) : pp. $142-145$.

Fitria Martanti. 2013.Gambaran sikap ibu primigravida trimester III tentang persiapan persalinan $d i$ BPS Finulia Sri Surjati Banjarsari Surakarta. Surakarta: Stikes Kusuma Husada. ISSN: 23387246

Hidayatun, dan Rima. 2016. Hubungan Pengetahuan Ibu Hamil TM III dengan Persiapan Persalinan di BPM Ny. Uning Marhandika. Midwifery Journal of STIKes Insan Cendekia Medika Jombang. 12 (1) : pp 1-6.

Kemenkes RI. 2012.Survei demografi dan kesehatan Indonesia. Jakarta: Kementrian Kesehatan RI.

Lee, 2015. Konseling Keluarga Pendekatan Teori Satir. Buist \& Dekovic

Mardiyaningsih. 2012. Hubungan antara Peran Suami dengan Kesiapan Ibu Hamil Trimester III dalam
Menghadapi Persalinan Di RB Rahayu Ungaran Kabupaten Semarang. Prosiding Ilmiah Nasional Kesehatan. Pp: 1-6.

Maryunani A, Puspita E. 2013.Bukusaku program perencanaan persalinan dan pencegahan komplikasi (P4K). Jakarta: TIM.

Notoatmodjo, 2010. Metodologi Penelitian Kesehatan, Jakarta : Rineka Cipta.

Prasetyawati Arsita E. 2012. Kesehatan ibu dan anak dalam MDG'S. Yogyakarta: Nuha Medika.

Prima Visi. 2016. Hubungan Pengetahuan dan Sikap Tentang Persalinan Dengan Kesiapan Primigravida Dalam Menghadapi Persalinan .Tesis. Universitas Sebelas Maret.

Riani, 2016. Hubungan Pengetahuan Ibu Hamil dan Dukungan Suami dengan Kepatuhan Melaksanakan Program Perencanaan Persalinan dan Pencegahan Komplikasi (P4K) di Kota Salatiga. JSK. 1 (4) : 179 - 185 .

Sherly. 2014. Faktor - faktor yang Mempengaruhi Pelaksanaan P4K di Puskesmas Air Dingin Kota Padang. KTI. Poltekkes Kemenkes Padang.

Steppi, Rosalina dan Eko. 2016. Hubungan Dukungan Suami dengan Kesiapan Ibu Hamil Menjelang Persalinan. Jurnal STIKes Ngudi Waluyo Ungaran. pp : 1-10.

WHO, 2016. Maternal Mortality. Diperoleh dari : http://www.who.int/mediacentre / factsheets/fs348/en/index.html [Diakses tanggal 04 April 2017] 